\title{
Looking through the eyes of Dyslexic Children: An Investigation into the Attitudes and Awareness of Selected Public School Teachers in Laguna
}

\author{
Maria Eva E. Diongco, Ed. D. ${ }^{\mathrm{a}, \mathrm{b}}$, Marie Ann S. Gonzales ${ }^{\mathrm{b}}$ - \\ ${ }^{a}$ mariaevadiongco@lspu.edu.ph \\ ${ }^{b}$ Laguna State Polytechnic University, College of Teacher Education - Graduate Studies and Applied Research, Laguna, 4009, \\ Philippines
}

\begin{abstract}
This descriptive study was conducted to determine the teachers' perception and level of awareness on pupils with dyslexia on phonological awareness, reading fluency, vocabulary, and comprehension and learning styles to improve their classroom performance and reading ability. The significant relationship between the teachers' perception on the level of disability of dyslexic pupils and their classroom performance was also measured. The respondents were thirty (30) public school teachers from the ten (10) selected schools in the Division of Laguna. A researcher-constructed questionnaire was used to gather the needed data. Descriptive as well as inferential statistics and multiple regressions were used to establish the quantitative dimensions of the problems posed. The results revealed that teachers' perception and level of awareness on pupils with dyslexia the students' performance and reading ability. The educators need to be sensitive to the wide range of ways in which dyslexic pupils may have difficulties as evidenced by the overall mean of 3.62, interpreted as highly evident. Classroom teachers need to have an understanding of the problems that a dyslexic child may have within the classroom situation. Hence, a great deal of misunderstanding of a child's behavior can be prevented. School administrators together with the stakeholders should set plans to provide teachers with special training on how to identify the approach needed to dyslexic pupils.
\end{abstract}

Published by IJRP.ORG. Selection and/or peer-review under responsibility of International Journal of Research Publications (IJRP.ORG)

1.1.1. Keywords: dyslexia; reading ability; learning styles; teacher's attitudes; awareness

\section{Introduction}

Reading is essential in modern societies; it is how to discover new things and how to develop a positive self-image. It is important because it helps to expand the mind and develops the imagination, but many children have dyslexia, a difficulty in learning to read. (Why reading is important, n.d.) 70-80\% of people with poor reading skills are likely dyslexic. One in five students, or $15-20 \%$ of the population, have a language based learning disability. Dyslexia is the most common of the language based learning disabilities. Nearly the same percentage of males and females has dyslexia (Dyslexia Facts and Statistics, n.d.). Dyslexia 
often arises from impaired phonological awareness, the auditory analysis of spoken language that relates the sounds of language to print. Behavioral remediation, especially at a young age, is effective for many, but not all, children. Neuroimaging in children with dyslexia has revealed reduced engagement of the left temporoparietal cortex for phonological processing of print, altered white-matter connectivity, and functional plasticity associated with effective intervention. Behavioral and brain measures identify infants and young children at risk for dyslexia, and preventive intervention is often effective. A combination of evidence-based teaching practices and cognitive neuroscience measures could prevent dyslexia from occurring in the majority of children who would otherwise develop dyslexia (Hoeft et al. 2006).

\subsection{Purpose of the Study}

The primary aim of the study was to determine the teachers' perception and level of awareness on pupils with dyslexia on phonological awareness, reading fluency, vocabulary, and comprehension and learning styles to improve their classroom performance and reading ability. This will provide the sufficient information and characteristics of a dyslexic pupil and could be utilized to monitor the progress of pupils identified with this special need.

\section{Literature Review}

There are no medications or medical treatments for dyslexia. While individuals may have cognitive or physical differences, disability is created through society's response to these differences. Hence, the response to difference is not cure or remediation of the individual, but to understand how unjust social systems create or exacerbate differences (Caravolas, 2009).

Applied to schools, disability studies in education (DSE) examines disability in schools as a social construction that results in social exclusion and oppression, as students with disabilities are routinely excluded from the educational opportunities presented to students without disabilities Disability studies have long engaged in critical analysis of the role of higher education, academia, and other institutions in constructing disability.

As Linton (1998) noted, learners with special educational needs can be caught in a spider's web due to their lack of being less successful as their peers. Reading helps train children to use abstract thinking, as they have to imagine other people, places and things while reading. Being better at reading might involve more practice of sitting down and concentrating on a task which could be useful for intelligence test performance (Shaywitz, 2014).

Rosenthal and Jacobson (2009) explained that in diagnosing dyslexia, there is a need to compare a person's reading ability to his cognitive ability, educational level or professional stature. Dyslexia is different; a person with a high IQ (cognitive ability comparable to a collegiate level) suffers from neurobiological disruption in the neural system for rapid reading resulting in extremely slow and effortful reading.

Phonological dyslexics as stated by Genard et al, (2008) have difficulty in applying phonic principles to unfamiliar words or pseudo-words. Surface dyslexics are weak at word identification and building sight vocabulary. These skills are essential for learning to read and spell. 
Teachers can help pre-school children ages 3 to 5 by providing phonological awareness instruction that is systematic and explicit integrated into daily activities including planned individual and group instructional sessions tailored to children's learning needs at all developmental levels (International Dyslexia Asso., 2011). Dyslexia cuts across class, age, and intelligence. All schools will have pupils with dyslexia and teachers of children of all ages need to be aware of the teaching methods and approaches which are most effective with these children.

Educators can foster reading development by providing kindergarten children with instruction that develops print concepts, familiarity with the purposes of reading and writing, age-appropriate vocabulary and language comprehension skills and familiarity with the language structure.

Lyon (2010) further claimed that youngsters having difficulties to read should be taught and integrated into textual reading formats to ensure sufficient levels of fluency, automaticity, and understanding.

The need for highly capable teachers is a constant theme in the literature on early childhood education. This is particularly true in the area of early literacy. The government has increased its efforts for the formal education and training of early childhood teachers as evidenced by the existence of government-funded prekindergarten programs. Strategies and guidelines on planning lessons, conducting an assessment, helping students with learning disabilities make this an essential reference and professional. (Birsh, 2011)

\section{Methodology}

\subsection{Selection of Respondents}

The respondents were the English language teachers from the ten (10) selected public schools handling learners whose foreign language was English.

\subsection{Preparation of the research instrument phase}

Researcher constructed questionnaire was developed by the authors comprised of four sections (30 items based on Likert scale) about the teachers' perception and level of awareness on pupils with dyslexia on phonological awareness, reading fluency, vocabulary and comprehension. Another section of the instrument was included to assess the relationship between the teachers' perception on the level of disability of dyslexic pupils and their classroom performance.

\subsection{Permission to conduct the study}

Upon completion of the required documents from DepEd for the desired group of respondents, request for the issuance on the authorization to the concerned school principals and school heads to conduct the study was made.

\subsection{Data collection, treatment and analysis of data}

Consolidation of the collected data. The data collected was subjected to the appropriate statistical treatment followed by the interpretation of the results and findings. 


\section{Results and Discussion}

\subsection{Level of Phonological Awareness}

Table 1 presents the level of phonological awareness of the pupils according to their teacher's perception. The statistical treatments used were mean, standard deviation (SD) and weighted mean.

Table 1. Phonological awareness of pupils

\begin{tabular}{llll}
\hline $\begin{array}{l}\text { Statements } \\
\text { The child... }\end{array}$ & Mean & SD & Verbal Interpretation \\
\hline 1. Identify a word in a sentence. & 2.88 & 0.35 & Moderately High \\
2. Recognize the same sounds. & 3.13 & 0.35 & Moderately High \\
3. Show the ability to separate words. & 2.75 & 0.46 & Moderately High \\
4. Understand the first sound in the word. & 3.50 & 0.53 & High \\
$\begin{array}{l}\text { 5. Understand the first sound at the end of the } \\
\text { word. }\end{array}$ & 3.13 & 0.64 & Moderately High \\
Weighted Mean & & 3.08 & Moderately High \\
\hline
\end{tabular}

The ability of the child to understand the first sound in the word was rated the highest, while there was an evident difficulty to identify a word in a sentence. This implies that there was a struggle with processing information in the level of phonological awareness based on their teachers' perceptions. The findings of Brode, DeLashmit and Pigott (2016) affirm that the cause of dyslexia is a phonological deficit. An effective evaluation has to be carefully planned at the beginning of the course to determine the level of understanding of students so as to implement a phonological awareness training to improve phonological processing skills.

\subsection{Level of Reading Fluency}

Table 2 shows the level of reading fluency of the students which was statistically treated using mean, SD, and weighted mean.

Table 2. Reading fluency of pupils

\begin{tabular}{llll}
\hline $\begin{array}{l}\text { Statements } \\
\text { The child... }\end{array}$ & Mean & SD & Verbal Interpretation \\
\hline 1. Can read fluently. & 2.75 & 0.46 & Moderately High \\
2. Pronounces the word correctly. & 2.88 & 0.35 & Moderately High \\
3. Can easily read the words. & 3.13 & 0.64 & Moderately High \\
4. Reads the word with proper emphasis. & 2.50 & 0.53 & Low \\
5. Gives his/her full attention on reading. & 3.00 & 0.53 & Moderately High \\
Weighted Mean & & 2.85 & Moderately High \\
\hline
\end{tabular}

Results showed that the pupils can easily read the words but had the greatest difficulty in reading the word with proper emphasis. It is believed that inability to acquire reading fluency can be considered as an indicator of learning disabilities. This supports the findings of Lewis (1998) that dyslexia is a learning disability that 
interferes with a person's ability to read, thus hindering one's educational goals. In addition, Ergul (2007) recommended that these students need to be urgently referred for evaluation and provided with special education services.

\subsection{Level of Vocabulary}

Table 3 illustrates the level of the vocabulary of the students which was statistically treated using mean, $\mathrm{SD}$, and weighted mean.

Table 3. Level of vocabulary of pupils

\begin{tabular}{llll}
\hline $\begin{array}{l}\text { Statements } \\
\text { The child... }\end{array}$ & Mean & SD & Verbal Interpretation \\
\hline $\begin{array}{l}\text { 1. Can blend, rhyme sounds, learning the alphabet, } \\
\text { linking letters with sounds. }\end{array}$ & 3.00 & 0.00 & Moderately High \\
$\begin{array}{l}\text { 2. Learns rules for spelling, spell words the way } \\
\text { they sound. }\end{array}$ & 3.00 & 0.76 & Moderately High \\
$\begin{array}{l}\text { 3. Can remember little words that cannot be } \\
\text { sounded out. }\end{array}$ & 3.25 & 0.46 & Moderately High \\
$\begin{array}{l}\text { 4. Can understand the story when read to him/her. } \\
\begin{array}{l}\text { 5. Can understand the story when read but } \\
\text { struggles in reading the story independently. }\end{array}\end{array}$ & 3.38 & 0.52 & Moderately High \\
Weighted Mean & 3.00 & 0.53 & Moderately High \\
\hline
\end{tabular}

As to the level of vocabulary, another learning difficulty to understand the story when read to him/her was found. Research indicates that the brains of people with dyslexia are organized differently than those without the disorder; causing difficulties processing meaningful information. Dyslexic students pose a particular challenge to academic staff because their difficulties are hidden (Riddell \& Weedon, 2006).

\subsection{Level of Comprehension}

Table 4 depicts the level of comprehension of the students which was statistically treated using mean, SD, and weighted mean.

Table 4. Level of comprehension of pupils

\begin{tabular}{lccc}
\hline $\begin{array}{l}\text { Statements } \\
\text { The child... }\end{array}$ & Mean & SD & Verbal Interpretation \\
\hline $\begin{array}{l}\text { 1. Can identify explicit information. } \\
\text { 2. Can express his/her ideas orally. }\end{array}$ & 3.25 & 0.46 & Moderately High \\
3. Can construct sentences on his/her own. & 3.00 & 0.53 & Moderately High \\
4. Can express himself/ herself. & 2.63 & 0.74 & Moderately High \\
5. Can do things at the same time. & 3.13 & 0.64 & Moderately High \\
Weighted Mean & 2.88 & 0.83 & Moderately High \\
\end{tabular}


In the level of comprehension, the ability to identify explicit information was rated the highest. This was identified as a major contributing factor in enhancing learning, as they are recognized as an effective tool to understand fully, thus helping the learners to regain their confidence in the classroom (Apag and Ona, 2014). It is appropriate to recommend that these students need to be urgently referred for evaluation and provided with special education services.

\subsection{Level of Classroom Performance}

Table 5 displays the level of classroom performance of the students which was statistically treated using mean, SD, and weighted mean.

Table 5. Level of classroom performance

\begin{tabular}{llll}
\hline Statements & Mean & SD & Verbal Interpretation \\
\hline 1. The child can interact with the teacher. & 3.13 & 0.35 & Moderately High \\
2. The child can easily understand the instruction. & 3.13 & 0.64 & Moderately High \\
3. The child comes to school well-oriented. & 3.25 & 0.71 & Moderately High \\
4. The child can do his/her activities. & 3.25 & 0.46 & Moderately High \\
5. The child participates in discussion. & 3.00 & 0.53 & Moderately High \\
\hline Weighted Mean & & 3.15 & Moderately High \\
\hline
\end{tabular}

The data above revealed that the level of classroom performance, a significant factor in the development of the learners was rated the highest in terms of coming to school in a well-oriented manner. This implies that the assurance in successfully doing the learner on his/her own is quite low. This was confirmed by Hodge (2017) that understanding the pupil's specific difficulties, and how they may affect the student's classroom performance can enable the teacher to adopt teaching methods and strategies to help the dyslexic child to be successfully integrated into the classroom environment.In order to be able to teach, as far as possible, according to each child's educational needs, it is essential to see him or her as a whole person, complete with individual strengths and weaknesses.

\subsection{Level of Reading Ability}

Table 6 shows the level of reading ability of the students which was statistically treated using mean, SD, and weighted mean.

Table 6. Level of Reading Ability

\begin{tabular}{llll}
\hline Statements & Mean & SD & Verbal Interpretation \\
\hline 1. The child can read continuously. & 3.25 & 0.46 & Moderately High \\
\hline 2. The child can pronounce the words correctly. & 3.13 & 0.64 & Moderately High \\
\hline 3. The child can retell what has been read. & 2.88 & 0.35 & Moderately High \\
\hline 4. The child can read the words. & 3.13 & 0.83 & Moderately High \\
\hline 5. The child understands what he/she needs. & 3.00 & 0.93 & Moderately High \\
\hline Weighted Mean & & 3.08 & Moderately High \\
\hline
\end{tabular}


The results on the level of reading ability, ranked the highest on the learner's difficulty to read continuously. This supports the findings of Vaughn, et al. (2010) that performing simple reading aloud in front of the class is a worse scenario for dyslexic learners. Early interventions, with ability of teachers to adapt to their individual learning needs would greatly influence their learning progress.

The tables above showed results of the teachers' perception and level of awareness on pupils with dyslexia on phonological awareness, reading fluency, vocabulary, and comprehension and learning styles to improve their classroom performance and reading ability.

\subsection{Relationship between the Teachers' Perception on the Level of Disability of Dyslexic Pupils and their Classroom Performance}

Table 7. Relationship between the Teachers' Perception on the Level of Disability of Dyslexic Pupils and their Classroom Performance

\begin{tabular}{|c|c|c|c|c|c|c|c|}
\hline Level of Disability & Mean & Performance & Mean & Df & r-comp & r-crit & Analysis \\
\hline \multirow{2}{*}{$\begin{array}{l}\text { Phonological } \\
\text { Awareness }\end{array}$} & \multirow{2}{*}{3.08} & $\begin{array}{l}\text { Classroom } \\
\text { Performance }\end{array}$ & 3.15 & 6 & 0.57 & 0.71 & NS \\
\hline & & Reading Ability & 3.08 & 6 & 0.48 & 0.71 & NS \\
\hline \multirow{2}{*}{ Reading Fluency } & \multirow{2}{*}{2.85} & $\begin{array}{l}\text { Classroom } \\
\text { Performance }\end{array}$ & 3.15 & 6 & 0.89 & 0.71 & S \\
\hline & & Reading Ability & 3.08 & 6 & 0.82 & 0.71 & S \\
\hline \multirow{2}{*}{ Vocabulary } & \multirow{2}{*}{3.13} & $\begin{array}{l}\text { Classroom } \\
\text { Performance }\end{array}$ & 3.15 & 6 & 0.85 & 0.71 & $\mathrm{~S}$ \\
\hline & & Reading Ability & 3.08 & 6 & 0.72 & 0.71 & S \\
\hline \multirow{2}{*}{ Comprehension } & \multirow{2}{*}{2.98} & $\begin{array}{l}\text { Classroom } \\
\text { Performance }\end{array}$ & 3.15 & 6 & 0.79 & 0.71 & $\mathrm{~S}$ \\
\hline & & Reading Ability & 3.08 & 6 & 0.82 & 0.71 & $\mathrm{~S}$ \\
\hline
\end{tabular}

At a glance, it can be seen that the teachers' perception in terms of the level of phonological awareness and the students classroom performance and reading ability have no significant relationships with one another. Between phonological awareness and classroom performance, results in no significant relationship. Reading fluency, vocabulary and comprehension has significant relationships with classroom performance and reading ability, as seen in the table. Thus, the hypothesis that there is no significant relationship between the teachers' perception of the level of disability of dyslexic pupils and their classroom performance is rejected. Classroom teachers need to have an understanding of the problems that dyslexic child may have within the classroom situation. Hence, a great deal of misunderstanding of a child's behaviour can be prevented. School 
administrators together with the stakeholders should set plans to provide teachers with special training on how to identify the approach needed to dyslexic pupils (Reid, 2016).

\section{Conclusion}

The results revealed that teachers' perception and level of awareness on students with dyslexia significantly affect the students performance and reading ability. All schools will have pupils with dyslexia and teachers of children of all ages need to be aware of the teaching methods and approaches which are most effective with these children.

\section{Recommendations}

In view of the findings and conclusions it was recommended to conduct close monitoring of students at risk of dyslexia in all educational institutions; this should be legally supported by the Philippine government to provide more training for teachers, school heads and supervisors. Thereby teachers dealing with dyslexic children will be flexible in their approach and will find a method that suits the students. Since there is no medication for dyslexia, schools could create linkages to a number of professionals who might help dyslexic pupils.

\section{References}

Australian Government response to recommendations of the Dyslexia Working Party Report 'Helping people with dyslexia: a national action agenda'(http://creativecommons.org/licenses/by/3.0/au/legalcode).

Birsh,Judith.,2011. Multisensory Teaching of Basic Language Skills. An effective instruction in the field of reading and dyslexia. Publisher: Brookes Publishing; 3rd edition (June 20, 2011); Language: English

Brode, E., DeLashmit,R. and Pigott, L. 2016. Phonological Awareness in Children with Dyslexia. https://gsa.memberclicks.net/assets/documents/2016-Convention/Handouts/brode\%20delashmit\%20pigottposterhandout.pdf

Caravolas, M. Volin J. And Hulme CV. 2005. Phoneme Awareness is a Key Component of Alphabetic Literacy Skills: Evidence From Czech and English Children.J. Child Psychology: 92: 107-139.

DLSU Researh Congress 2014. Research Development Session. xsite.dlsu.edu.ph/conferences/dlsu_research_congress.../researchdevelopment.asp Abstract, Meldie Apag, Sherwin Ona. 1100-1120, RDS-V-18

Dyslexia Facts and Statistics-Austin Learning Solutions. www.austinlearningsolutions-dyslexiafactsand statistics.html.

Hoeft, F., Hernandez,A., McMillon, G. Et al. 2006. Nueral Basis of Dyslexia: A Comparison Between Dyslexic and Non-Dyslexic Children Equated for Reading Ability. J. NueroScience: 26: 10700-10708.

Hodge, Patricia. 2017. A Dyslexic Child in the Classroom. https://www.dyslexia.com/about-dyslexia/understanding-dyslexia/guide-forclassroom-teachers/

Genard, S. , R. Joshi, and E. Houghen. 2009. Pre-School Language and Literacy. Retrieved from: http://www.dyslexia.com/library/classroom.html

Ergul, Cevriye. 2007. Evaluation of Reading Performances of Students with Reading Problems for the Risk of learning Disabilities. https://files.eric.ed.gov/fulltext/EJ1000909.pdf

International Dyslexia Association (March, 2011). Teacher Preparation: Key to Effective Instruction. The Examiner. Retrieved April 2, 2011 from www.interdys.org. 
Lewis, Hamilton. 1998. F1 Champion Speaks About His Dyslexia. htpps://thepowerofdyslexia.com/lewis-hamilton.

Linton, S. Claiming Disability: Knowledge and Identity; NYU Press: New York, NY, USA, 1998.

Lyon, GR, Shaywitz, BA. 2010. A Definition of Dyslexia. Ann Dyslex: 53: 1-14.

Magna Carta for Disabled Persons. adpi-mpc.tripod.com/id20.html

Nation, K. Cocksey, J. Taylor, JSH and Bishop, DVM. 2010. A Longitudinal Investigation of Early Reading and Language Skills in Children with Poor Reading Comprehension. J. Child Psychology: 51: 1031-1039.

Pollock, J., Waller, E. and Pollitt, R. (2004). The Effective Teacher's Guide to Dyslexia and Other Learning Difficulties. Journal of Research in Reading 23, 28- 40.

Reid, Gavin, 2016. Dyslexia, Dyspraxia, Literacy and Learning Assessment. https//www.dr.gavid.com.

Republic Act 10754 in 2016. www.officialgazette.gov.ph/2016/03/23/republic-act-no-10754

Republic Act 9442 in 2007. https://advocacine.wordpress.com/republic-act-9442

Riddell, S., and Weedon, E. 2006. Key Perspectives on Dyslexia, Dyslexic students and the concept of fair assessment. https://books.google.com.ph

Rosenthal and Jacobson. 2009. Dealing with Dyslexia. Occupational Health. 61: (11), 18-20.

Shaywitz M. 2016. Perceptions and Knowledge of Pre-Service and In-service Educators about Early Reading Instruction. Annals of Dyslexia.51:97-120.

Torgessen, JK. 2005. Recent Discoveries on Remedial Interventions for Children with Dyslexia. The Science of Reading: A Handbook. Blackwell Publishing, Oxford; 521-537.

Vaughn, S. Cirino, PT, Wanzek, J et al. 2010. Response to Intervention For Middle School Students with Reading Difficulties: Effects of a Primary and Secondary Intervention. Sch. Psychology Rev. 39: 3-21.

Why Reading is Important- One World Literacy Foundation. htpps//www.onewroldliteracyfoundation.org/index.php.why-reading-isimportant $/ \mathrm{html}$ 